\title{
INVESTIGATING THE CITIZENS' INTENTION LEVEL IN ENVIRONMENTAL IMPACT ASSESSMENT PARTICIPATION THROUGH AN EXTENDED THEORY OF PLANNED BEHAVIOR MODEL
}

\author{
PERSADA S.F F $^{1 *}$ \\ LIN S. $C^{1}$ \\ NADLIFATIN R. ${ }^{1}$ \\ RAZIF M. ${ }^{2}$
}

\author{
${ }^{1}$ Department of Industrial Management \\ National Taiwan University of Science and Technology \\ 43 Keelung Rd Da'an Dist, Taipei 106, Taiwan \\ ${ }^{2}$ Department of Environmental Engineering \\ Institut Teknologi Sepuluh Nopember (ITS) \\ Campus ITS Sukolilo, Surabaya 60111, Indonesia
}

Received: 14/06/2015

Accepted: 02/12/2015

*to whom all correspondence should be addressed:

Available online: $11 / 12 / 2015$ e-mail: d10101807@mail.ntust.edu.tw

\section{ABSTRACT}

This study aims to measure citizens' behavior intention (BI) in Environmental Impact Assessment (EIA) participation. An extended theory of planned behavior (TPB), which includes perceived government support and perceived environmental concern, is used as the predictor model. A total of 240 questionnaire data, gathered from citizens of Indonesia, was analyzed by using structural equation modeling. The analysis result shows that the TPB model revealed 60 percent of citizens' BI in EIA participation. Another finding revealed perceived behavior control as a key determinant factor. Practical recommendations suggested based on the result can be used as references by EIA policy makers and practitioners to increase citizens' intention in EIA participation.

Keywords: TPB, Citizens, EIA participation, Behavior intention

\section{Introduction}

The societies are continuously facing the inevitable challenge of overcoming the environmental damage. Urban development activities, which have intensively conducted by humans to overcome the growth of the population, produce a huge negative impact on the environment (El Araby, 2002; Pimentel et al., 2007; Xian et al., 2007). Although some individuals are aware of the environmental problems, in large scale, the role of big organizations is essential to manage these unavoidable impacts. Because environmental damage is a worldwide issue, it requires serious actions from all institutions, especially from the government, which has the control authority to monitor the situation. Participation of government is expected to extend the environment existence for the future generation. Several pro-environmental research studies were extensively performed as one of the approaches to maintain the existence of sustainable environment (Jim, 2004; Lucas et al., 2008; Persada et al., 2014). One representative example of pro-environmental realization, performed by government, is through the activity of environmental impact assessment (EIA). Introduced in the 1960s by the US National Environmental Policy Act, EIA can be described as a mechanism carried out to

Persada S.F., Lin S.C., Nadlifatin R. and Razif M. (2015), Investigating the citizens' intention level in environmental impact assessment participation through an extended theory of planned behavior model, Global NEST Journal, 17(4), 847-857. 
assess potential effects that possibly emerge during a physical development project (Glasson et al, 1999). The idea of managing potential environmental impacts caused by human activities has attracted and adapted by many countries in the following years (Tang et al., 2005). Living creatures, including human beings, are considered as the central attention of EIA in every aspect of physical development stages. Previous EIA research studies were highlighted the importance of citizens' consideration in developing a proper policy and regulation (O'Faircheallaigh, 2010; Glucker et al., 2013). Thus, societies have the role not only to maintain environmental balance, but also as an object in the EIA study. The assessment aims to make sure that the resulted recommendations and policies cover the potential impacts on citizens' living in the surrounding area within physical, biological, social, cultural, economic and public health aspects.

While many studies focused on quantitative approaches to improve the EIA process (Janssen, 2001; Kaya and Kahraman, 2011; Wanderer and Herle, 2015), few described the improvement through EIA qualitative assessment, especially from behavior perspective. This study, therefore, aims to investigate the citizens' intention to participate in the EIA process. This study is also the first to address the extended TPB as the assessment model on Indonesian citizens to the EIA activity in their surrounding environment. TPB model was selected because the model able to describe most of the human behavior and it was also conveniently used by many researchers in describing pro-environmental activity (Cordano and Frieze, 2000; Bamberg, 2003; Fielding et al., 2008; Han et al., 2010; Park and Yang, 2012). Indonesia, as the $4^{\text {th }}$ largest populated and also a developing country, is selected to represent the massive implementation of the EIA in development activity. If the model explains the citizen's intention to participate the EIA project's well, then an improvement or better implementation can be suggested based on the study, and thus results to increase the citizens' current intention level of participating. Increasing citizens' intention to participate in EIA process will help EIA-related agencies and project owner in determining the number of citizens to participate in order to collect the precise data used as the EIA analysis source and to provide accurate recommendations in EIA study. The rest of this paper is organized as follows. Section 2 explores literatures regarding the EIA process in Indonesia and the elements of TPB. A constructed model and hypotheses are also proposed in this section. Section 3 presents research method. Section 4 describes data analysis results and some findings of the research. Section 5 summarizes this study by drawing some conclusions that can be used as references and recommendation for conducting further research.

\section{Theoretical model}

TPB is a well-known psychological model proposed by Ajzen (1991) in an effort to predict human behavior intention. TPB was broadly adapted by researchers from different fields to assess individual and community perception as well as to understand individual behavior and behavior within a designated community. TPB is used to predict behavior intention (BI), which can be constructed by three factors: attitude (AT), subjective norms (SN) and perceived behavior control (PBC). According to Ajzen (1991), AT is described as how an individual expresses his/her favorable or unfavorable perception of preferences to perform a specific behavior. SN factor can be seen as the individual perceptions that come from the social environment that is considered to have strong influences on an individual when performing a certain behavior. PBC can be described as individual beliefs concerning whether he or she has the access to necessary resources and opportunities to perform the behavior. BI is a person's motivation in the sense of his/her decision to exert effort to execute a particular behavior (Conner and Armitage, 1998). It is assumed that when an individual has feelings of positive attitude, subjective norms and perceived behavior control, the intention to perform the behavior will increase (Ajzen, 1985). In this research, two factors that include perceived government support (PGS) and perceived environmental concern (PEC) were added to the model to analyze the EIA process, as depicted in Figure 1. 


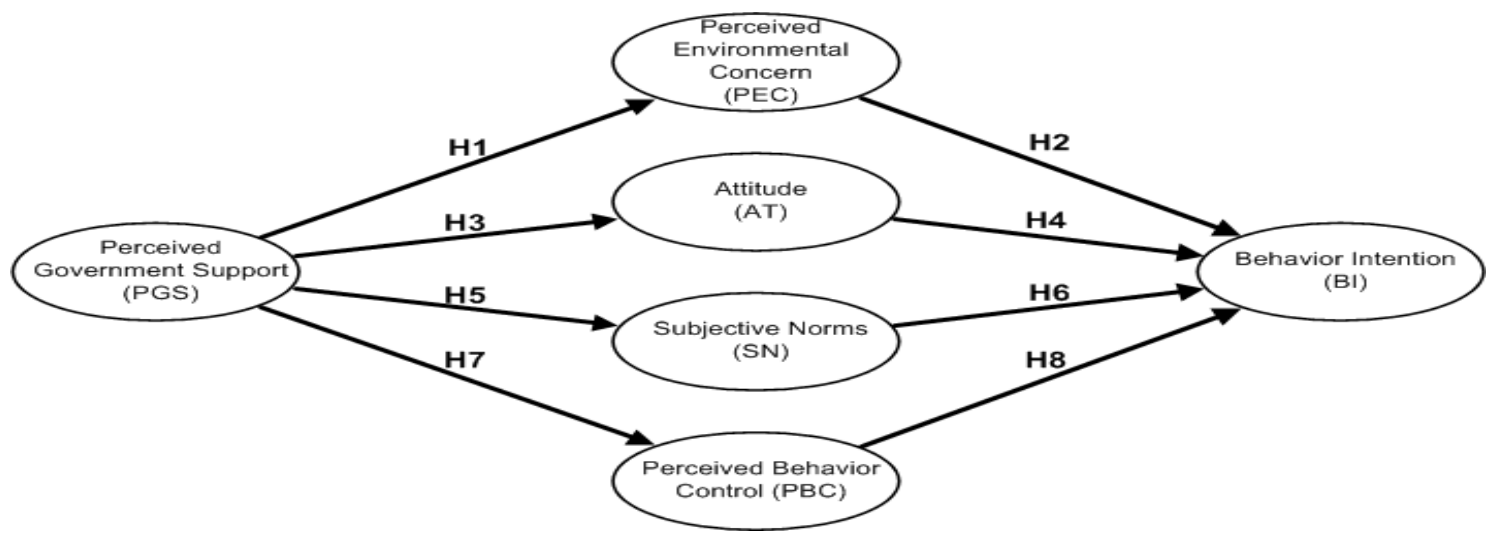

Figure 1. An extended TPB model

The role of government, as a control authority, can substantively influence any business operation that includes urban development activities (McKee and Wang, 2006; Tan and Teo, 2000). Government can affect the development activities by regulating the rules and enforcing such regulations and physical procedures that widely cover issues such as safety, health, norms, and economics. As a consequence, the government is in a supreme position to support, grant, or to obstruct the development activities in order to minimize negative impacts that may affect the environment and the society. Thus, PGS can be best seen as an individual perception that any resource, regulation, facility and support given by the government are considered to be able to accommodate the individual to perform a specific behavior (Nadlifatin et al., 2014). Indonesian government's EIA regulation details its supports to the environment and society regarding project development (Government of Indonesia, 2009; Government of Indonesia, 2012). The regulation also encourages the society to concern about the environment in the development activities. Environmental concern is roughly associated with the awareness of environmental impacts that would drive individual perception to behave in pro-environmental action (Fujii, 2006). Environmental concern also can best be understood as an evaluation of individual perception towards the environment (Fransson and Garling, 1999). The essence of environmental concern will help individual to behave more environmental friendly (Chen and Tung, 2014). Thus, PEC can be described as an individual feeling concerning with any physical activities leading to pro-environmental consequences. Studies have confirmed that environmental concern has positively influenced the individual psychological intention to perform a pro-environmental activity, both directly (Fujii, 2006; Han et al., 2010; Nadlifatin et al., 2014) and indirectly (Bamberg, 2003; Chen and Tung, 2014). Fujii, (2006) verified that there was a positive correlation between environmental concern and the intention of garbage reduction in Japan. His study explained that the positive relationship may essentially happened because the recycling method, which is used as a primary method for garbage reduction in Japan, has been intensively promoted by the Japanese government as its support to the environmental activities. Similarly, the Government of Indonesia issues EIA to show its support to the environmental protection and to prevent the environmental damage that might occur in development activities (Government of Indonesia, 1999). Based on these studies, we hypothesize that government support can accelerate citizens' intention to embody pro-environmental behavior, including their participation intention for EIA process. The proposed hypotheses consist of PGS and PEC factors as a predictor of $\mathrm{BI}$ are described as follows:

H1: PGS is positively related to PEC of citizens in EIA participation.

H2: $\mathrm{PEC}$ is positively related to $\mathrm{BI}$ of citizens in EIA participation.

AT in this research can be defined as an individual's likely or unlikely perception to participate in the EIA process. In terms of government policy, Indonesian government provides project owner a framework of regulations (Figure 2) for interacting with citizens. Citizens have duration of 10 working days to submit their 
suggestions, opinions and feedbacks (SOF) through the mail or any available media along with their personal identification. During the public socialization and consultation stage, citizens and project owner can interact with each other for information exchange by means of workshop, seminar, group discussion, or any suitable two-way communication method (Ministry of Environment of Indonesia, 2012c). The frequent stage of participation and many options of communication channels are expected to arouse citizens' favorable perception to involve in EIA participation. Hence, the following hypotheses are created to test the attitude:

H3: PGS is positively related to AT of citizens in EIA participation.

H4: $\mathrm{AT}$ is positively related to $\mathrm{BI}$ of citizens in EIA participation.

Together with AT in the Theory of Reasoned Action, as the source of the TPB model (Ajzen, 1991), SN is wellknown as a fundamental factor in TPB. This study considers SN as individual perceptions formed by a group of people that have important roles in the EIA process. In the EIA public involvement process, SN comprises of project owner and citizens' representative. The government, acting as a monitor and a control authority, provides both the project owner and citizens with EIA guideline and the project owner is advised to place citizens' priority concerns about the surrounding environment on top of construction activities. On the document review stage, citizens' representative acts as an EIA commission member and has the authority to assess and determine whether the project is feasible within 75 working days. If the citizens' representative did not approve the content of EIA document, feasibility permit would not be issued. Citizens' representative also serves as a liaison to link project owner and citizens by providing mutual information on EIA process. For instance, citizens' representative can suggest the project developer to hire local skilled people to work on that project. Thus, the role of government regulation serves as a platform to support both project owner and citizens' representative to work together with meaningful rules to obey with, and this is proposed in the following hypotheses:

H5: PGS is positively related to SN of citizens in EIA participation.

H6: $\mathrm{SN}$ is positively related to $\mathrm{BI}$ of citizens in EIA participation.

PBC in this study is an individual belief concerning whether he or she has the necessary resources and opportunities to participate in the EIA process. Research on pro-environmental studies such as Chen and Tung's, (2014), study revealed that PBC is a better predictor for BI than A and SN. They explained that it was because consumers put their perception of their ready availability to visit green hotel as one of the most important determinant factors. Similarly, in the EIA process, citizen's internal resource such as availability, working competency, skill, and confidence are considered as PBC when he/she contributes at the assessment stage. EIA process also provides the opportunity through the project owner to select the available local skilled employee to participate in the development activities. The recruiting process of skilled local citizens can be performed at the public consultation stage and monitored by the government. Therefore, hypotheses regarding the relationships between citizens' perceived behavior control and perceived government support as well as behavior intention will be examined as follows:

H7: PGS is positively related to PBC of citizens in EIA participation.

H8: $\mathrm{PBC}$ is positively related to $\mathrm{BI}$ of citizens in EIA participation.

\section{Methodology}

\subsection{Instrument development}

This study builds an extended TPB model and a questionnaire is developed as the instrument for collecting the data. The questionnaire is comprised of two sections in which the first section includes 17 observed variables that are intended to measure 6 latent variables in the model as shown in Table 1.The other section is to collect demographic and background information of the respondents such as their place of origin and 
age. Specifically, the 17 observed variables, which include PGS, PEC, AT, SN, PBC and BI, are assessed by a five-point Likert scale that ranges from 1 as "I strongly disagree" to 5 as "I strongly agree". The questionnaire was attached along with the EIA flow as shown in Figure 2 as well as the related government regulations and was distributed in a span of three months from November 2013 to April 2014. Both online and paper based questionnaires were used to collect a random sampling from citizens.

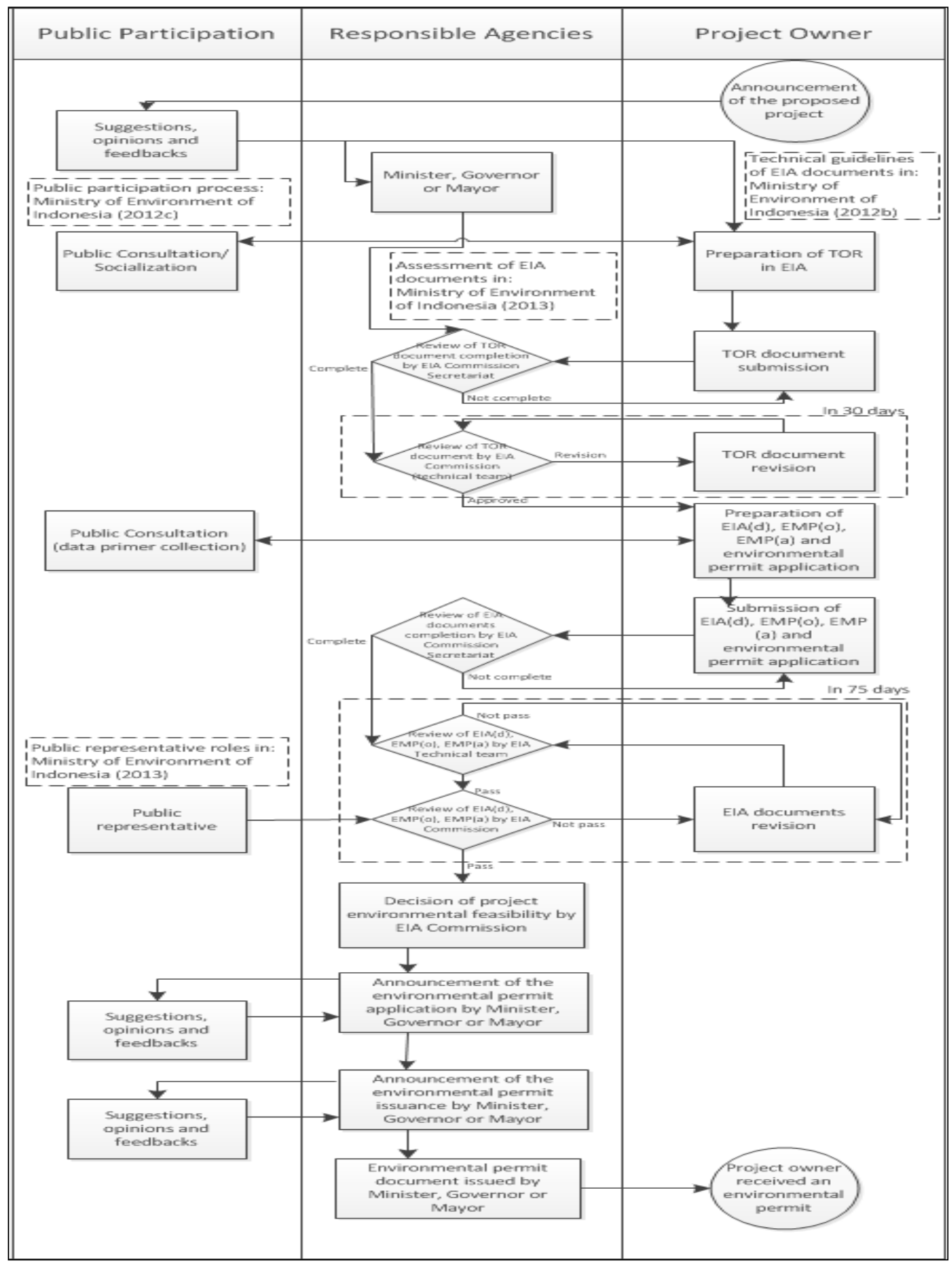

Figure 2. EIA public participation process in Indonesia (Government of Indonesia, 2012; Ministry of Ministry of Environment of Indonesia, 2012a; Environment of Indonesia, 2012b; Ministry of Environment of Indonesia, 2012c; Ministry of Environment of Indonesia, 2013) 
Table 1. Descriptive statistic

\begin{tabular}{ll}
\hline Item & Question and adapted source \\
\hline PGS1: & I feel I have a choice to use the strategies provided by the government for participating in the \\
& EIA process \\
PGS2: I feel I have a choice to participate in an environmental program established by the government \\
such as the EIA process. \\
PGS3: The government endorses the regulation to allow citizens participate in the EIA process \\
PEC1: I am extremely worried about the state of the world's environment and what it will mean for my \\
PEC2: $\quad$ Mankind is severely abusing the environment, hence it makes me want to participate in EIA \\
PEC3: $\quad$ When humans interfere with nature, it often produces disastrous consequences, it is concerning \\
PBC1: I have the knowledge and time to participate in the EIA process. \\
PBC2: I have resources, time, ability and opportunities to participate in the EIA process. \\
SN1: $\quad$ Most people who are important to me think I should participate in the EIA. \\
SN2: $\quad$ Most people who are important to me would want me to participate in the EIA process. \\
SN3: $\quad$ People whose opinions I value would prefer that I participate in the EIA process. \\
AT1: $\quad$ For me, participating in EIA process when project development occurs is extremely wise \\
AT2: $\quad$ For me, participating in EIA process is favorable \\
AT3: $\quad$ For me, participating in EIA process is enjoyable \\
BI1: I am willing to participate in the EIA process \\
BI2: I plan to participate in EIA process when project development is conducted \\
BI3: I will make an effort to participate in EIA process
\end{tabular}

\subsection{Analytical assessment}

The collected data is analyzed by testing the convergent and discriminant validity of individual indicator that is derived from each questionnaire. The indicator scale is tested based on the three criteria suggested by Fornell and Larcker (1981), Chin (1998), and Cheung and Vogel (2013), namely Factor loadings (FL), composite reliability (CR), and average variance extracted (AVE). Many researchers agree upon the minimum value for a good indicator as follows: FL as well as CR should exceed 0.7 (Cheon et al., 2012; Cheung and Vogel, 2013) and AVE must exceed 0.5 (Hair et al., 1998; Cheung and Vogel, 2013). Cronbach's $\alpha(\alpha)$ (Cronbach, 1951) is also widely used to test the questionnaire's reliability and a value over 0.7 is considered acceptable (Nunnally, 1978; Cheung and Vogel, 2013).

The model fit assessment was performed after data analysis. Several parameters (Hooper et al., 2008) that include root mean square error of approximation (RMSEA), root mean square residual (RMR), normed fit index (NFI), comparative fit index (CFI), and goodness of fit (GFI) were used. The values for RMSEA and RMR are analyzed with the maximum value of 0.08 . For $\mathrm{CFI}, \mathrm{NFI}$, and $\mathrm{GFI}$, they are analyzed with minimum value of 0.9 .

\section{Results and discussion}

\subsection{Data analysis}

A total of 240 respondents, consisting of ages from 21 to 61 years old, returned the questionnaire. All the respondents fulfill the minimum requirements of a full Indonesian citizenship right. They came from three 
different regions of Indonesia, where 224 were from the 27 cities of the western region, 14 were from the four cities of the central region, and 2 were from the one city of the eastern region. This sample proportion is also similar to the population data of Central Agency on Statistic of Indonesia (2010), where the western region has more population than central and eastern regions. This demographic results are good in representing the behavior of adult citizens as well as the distribution of development in each region to answer the 17 observed variables. A confirmatory factor analysis by using structural equation modeling (SEM) is used to further analyze the 17 observed variables. As a first SEM measurement, the collected data's reliability and convergent validity were tested. As it can be seen in Table 2, the average value of each factor was above 3.49, which reveals that respondents provides agreed answer to the importance of the six factors in the EIA process. In Table 2, the value of FL, Cronbach $\alpha$ and CR are all above 0.7, and the value of AVE is above 0.5. Thus, the data reliability and convergent validity are hence statistically satisfied.

Table 2. Reliability and convergent validity result

\begin{tabular}{llllllcc}
\hline Factor & \multicolumn{1}{c}{ Item } & \multicolumn{1}{c}{ Mean } & \multicolumn{1}{c}{ StDev } & FL & $\alpha$ & CR & AVE \\
\hline PGS & PGS1; PGS2; PGS3 & $3.783 ; 3.662 ; 3.654$ & $0.860 ; 0937 ; 0.934$ & $0.730 ; 0.847 ; 0.714$ & 0.8147 & 0.8089 & 0.5867 \\
\hline PEC & PEC1; PEC2; PEC3 & $4.138 ; 3.938 ; 4.129$ & $0.859 ; 0.929 ; 0.811$ & $0.773 ; 0.789 ; 0.777$ & 0.8216 & 0.8230 & 0.6097 \\
\hline PBC & PBC1; PBC2 & $4.054 ; 3.863$ & $0.809 ; 0.804$ & $0.783 ; 0.804$ & 0.7725 & 0.7763 & 0.6345 \\
\hline SN & SN1; SN2; SN3 & $3.596 ; 3.492 ; 3.608$ & $0.910 ; 0.863 ; 0.821$ & $0.768 ; 0.777 ; 0.733$ & 0.8025 & 0.8035 & 0.5769 \\
\hline AT & AT1; AT2; AT3 & $4.150 ; 4.317 ; 4.338$ & $0.815 ; 0.754 ; 0.742$ & $0.728 ; 0.889 ; 0.794$ & 0.8422 & 0.8471 & 0.6502 \\
\hline BI & BI1; BI2; BI3 & $3.992 ; 3.958 ; 3.925$ & $0.803 ; 0.796 ; 0.789$ & $0.797 ; 0.780 ; 0.781$ & 0.8348 & 0.8291 & 0.6179 \\
\hline
\end{tabular}

The next measurement is to find a model fit and to test the proposed hypotheses. A model fit analysis was employed to measure the proposed model based on five indicators as shown in Table 3. The value of the five indicators all passed its associated threshold and hence the proposed model is considered to be robust and predictive. A further statistical testing of the proposed hypotheses resulted to eight positive relationships. Bootstrapping (Zimmer-Gembeck et al., 2006; Lin et al., 2014) were employed to measure direct and indirect path estimates and their significance of these positive relationships.

Table 3. Statistical summary of model fit

\begin{tabular}{lll}
\hline Model fit parameters & Result in this study & Threshold \\
\hline Root mean square error of approximation (RMSEA); Root mean square residual (RMR) & $0.052 ; 0.038$ & $\mathrm{n} \leq 0.08$ \\
\hline Normed fit index (NFI); Comparative fit index (CFI); Goodness of fit (GFI) & $0.908 ; 0.961 ; 0.919$ & $\mathrm{n} \geq 0.90$
\end{tabular}

Table 4. Effects of the variables on the behavior of EIA participation

\begin{tabular}{ccccccc}
\hline & \multirow{2}{*}{ Factor } & \multicolumn{2}{c}{ Direct effect } & \multicolumn{2}{c}{ Indirect effect } & \multirow{2}{*}{ Hypothesis } \\
\cline { 3 - 5 } & & Estimate $(\beta)$ & $\mathrm{P}$ & Estimate $(\beta)$ & $\mathrm{P}$ & \\
\hline 1 & $\mathrm{PEC} \leftarrow \mathrm{PGS}$ & 0.670 & $0.003^{* * *}$ & - & - & H1: Supported \\
2 & $\mathrm{AT} \leftarrow \mathrm{PGS}$ & 0.544 & $0.002^{* * *}$ & - & - & H3: Supported \\
3 & $\mathrm{SN} \leftarrow \mathrm{PGS}$ & 0.509 & $0.002^{* * *}$ & - & - & H5: Supported \\
4 & $\mathrm{PBC} \leftarrow \mathrm{PGS}$ & 0.473 & $0.005^{* * *}$ & - & - & H7: Supported \\
5 & $\mathrm{BI} \leftarrow \mathrm{PGS}$ & - & - & 0.574 & $0.002^{* * *}$ & \\
6 & $\mathrm{BI} \leftarrow \mathrm{PEC}$ & 0.176 & $0.045^{* *}$ & - & - & H2: Supported \\
7 & $\mathrm{BI} \leftarrow \mathrm{AT}$ & 0.137 & $0.065^{*}$ & - & - & H4: Supported \\
8 & $\mathrm{BI} \leftarrow \mathrm{SN}$ & 0.346 & $0.002^{* * *}$ & - & - & H6: Supported \\
9 & $\mathrm{BI} \leftarrow \mathrm{PBC}$ & 0.436 & $0.001^{* * *}$ & - & - & H8: Supported \\
\hline$* * *: \mathrm{p} \leq 0.01, * *: \mathrm{p} \leq 0.05, *: \mathrm{p} \leq 0.1$ & & & &
\end{tabular}


As it has shown in Table 4, hypothesis 1 has the highest path coefficient value $(\beta=0.670)$ compare to other correlations. Among the four factors PEC, PBC, SN, A that are directly related to $\mathrm{BI}$, hypothesis $8(\beta=0.436)$ has the highest direct correlation coefficient. The coefficients of each factor's R-square are consisting of: 0.45 of PEC, 0.30 of AT, 0.26 of SN, 0.22 of PBC. Because the R-square of BI in this study has reached $60 \%$ (R2= 0.60 ), the proposed model is well supported and BI represents citizens' intention to participate in the EIA process appropriately.

\subsection{Discussion}

The results of this study have exhibited that our exploration model validated positive relationships among its six latent factors of PGS, PEC, AT, SN, PBC, and BI. The strongest and significant path coefficient attained in the relationship between PGS and PEC $(\beta P G S \rightarrow P E C=0.670)$ indicates that the government has a dominant role in influencing citizens for pro-environmental concern. Clearly, Indonesian government issued an EIA as one of the approaches to encourage the citizens to concern more about the environmental activity in local society. Another positive correlation, between PGS and AT (BPGS $\rightarrow A T=0.544)$, has indicated how Indonesian government tried to attract the individual attitude in the EIA process. The basic presumption applied in EIA is that when the procedures are favorable to follow, citizens tend to be more encouraged to participate in the EIA process. Positive correlation between PGS and SN ( $\beta P G S \rightarrow S N=0.509)$ has reflected how the government provides the liaison to relevant roles in the EIA process. Project owner and citizens' representative, as the relevant roles, has more occasion to convince the local citizens to participate during the document arrangement stage in the EIA process. The individuals who have internal capabilities will notably bring beneficial influence to the government and the project owner. Thus, the positive correlation between PGS and PBC ( $\beta P G S \rightarrow P B C=0.473)$ has indicated the benefits obtained from the collaboration of both local competent citizens and the project owner in the project. The indirect correlation between PGS to $\mathrm{BI}$ $(\beta P G S \rightarrow B I=0.574)$ describes that the main purpose of Indonesian government' support is to attract citizens' intention to participate in the EIA process.

The interesting finding of this study is that the relationship between PGS and PEC, as the highest path coefficient, has contributed low influence to $\mathrm{BI}(\beta P E C \rightarrow \mathrm{BI}=0.176)$. Commonly, the strongest antecedence path coefficient correlation became the major predictor for $\mathrm{BI}$, but it was not applied in our model. A possible reason is that Indonesian citizens are not aware of environmental concern, which can be evidenced through higher occurrence rate of environmental damage cases (Delinom et al., 2009). The study suggests to intensively promoting and educating regarding the importance of pro-environmental activity to arouse the citizens' concern. Presumably, the influence of perceived environmental concern to behavior intention is increased and hence the value of its correlation coefficient will be higher. The lowest path coefficient captured between $\mathrm{A}$ and $\mathrm{BI}(\beta \mathrm{AT} \rightarrow \mathrm{BI}=0.137)$ has denoted that attitude brings low influence to citizens' intentions. A possible reason is that the favorable facilities provided by the government to interact the citizens' attitude do not meet their expectations. Hence, the study suggests the government to collect the citizens' aspiration regarding their expected conditions in order to increase the correlation value between $\mathrm{A}$ and $\mathrm{BI}$. The high path coefficient value between $\mathrm{SN}$ and $\mathrm{BI}(\beta S N \rightarrow B \mathrm{~B}=0.346)$ has confirmed that individuals' intentions are no doubt influenced by people who plays an important role in the EIA process. The primary contributor of $\mathrm{BI}$ is $\mathrm{PBC}$, which has the highest total path coefficient value among all antecedents of $\mathrm{BI}(\beta P B C \rightarrow B I=0.473$ and $\beta P B C \rightarrow B I=0.436)$. This result is in accordance with recent research on pro-environmental behavior such as Chen and Tung's (2014) green hotel study, which revealed the dominant factor of PBC to BI. Based on this finding, the study can comfortably suggest that in order to arouse citizens' intentions through PBC, the strategy of emphasizing the advantages, such as employment opportunities based on the citizens' skill and resource in the EIA process to be practical and valuable. Furthermore, in the final measurement, the proposed model's variance percentage of behavior intention is approximately $60 \%$ ( $R 2=0.60)$, which means the six measurement indicators are able to represent 60 percent of total citizens' intentions in EIA participation. Our 
proposed model is comfortably comparable to similar pro-environmental behavior studies that used TPB as an exploration model (Bamberg, 2003; Han et al., 2010; Park and Yang, 2012).

\section{Conclusion}

This research extends the original TPB model proposed by Ajzen, (1991) by taking the perceived government support and perceived environmental concern as the additional factors to explore the citizens' behavior intention level in the EIA participation process. The result shows that the perceived government support substantively and positively affects individual perceived environmental concern, attitude, subjective norms, and perceived behavior control. Additionally, perceived government support has highest coefficient value to perceived environmental concern. Among the four promising predictors, the perceived behavior control is notably the key determinant to influence the citizens' EIA participation intention. Hence the study suggests that the government and project owner give emphasis to the benefits and opportunities that citizen would obtain in the EIA process through their participation and through their capabilities as a contributor.

In summary, this study affirms the convenience of applying extended TPB approach to measure citizens' behavior intention in the EIA participation process. All of the eight positive correlations proposed in the hypotheses are validated. Increasing citizens' intention to participate in EIA process will help the government officials and the project owner to collect more accurate data from participating citizens, enhance the EIA analysis, and provide better recommendations for EIA process. Finally, future research should explore other factors, which contribute to approximately 40 percent of the variance that might affect citizens' EIA participation intention.

\section{References}

Ajzen I. (1985). From intentions to actions: A theory of planned behavior: Springer.

Ajzen I. (1991), The theory of planned behavior, Organizational Behavior and Human Decision Processes, 50(2), 179-211.

Bamberg S. (2003), How does environmental concern influence specific environmentally related behaviors? A new answer to an old question, Journal of Environmental Psychology, 23(1), 21-32.

Central Agency on Statistic of Indonesia, (2010). Population of Indonesia by Province 1971, 1980, 1990, 1995, 2000 and 2010. Available: http://www.bps.go.id/linkTabelStatis/view/id/1267

Chen M.-F. and Tung P.-J. (2014), Developing an extended Theory of Planned Behavior model to predict consumers' intention to visit green hotels, International Journal of Hospitality Management, 36(0), 221-230.

Cheon J., Lee S., Crooks S.M. and Song J. (2012), An investigation of mobile learning readiness in higher education based on the theory of planned behavior, Computers and Education, 59(3), 1054-1064.

Cheung R. and Vogel D. (2013), Predicting user acceptance of collaborative technologies: An extension of the technology acceptance model for e-learning, Computers and Education, 63(0), 160-175.

Chin W.W. (1998), The partial least squares approach to structural equation modeling, Modern methods for business research, 295(2), 295-336.

Conner M. and Armitage C.J. (1998), Extending the theory of planned behavior: A review and avenues for further research, Journal of applied social psychology, 28(15), 1429-1464.

Cordano M. and Frieze I.H. (2000), Pollution reduction preferences of US environmental managers: Applying Ajzen's theory of planned behavior, Academy of Management Journal, 43(4), 627-641.

Cronbach L.J. (1951), Coefficient alpha and the internal structure of tests, Psychometrika, 16(3), 297-334.

Delinom R.M., Assegaf A., Abidin H.Z., Taniguchi M., Suherman D., Lubis R.F. and Yulianto E. (2009), The contribution of human activities to subsurface environment degradation in Greater Jakarta Area, Indonesia, Science of The Total Environment, 407(9), 3129-3141. 
El Araby M. (2002), Urban growth and environmental degradation: The case of Cairo, Egypt. Cities, 19(6), 389-400.

Fielding K.S., McDonald R. and Louis W.R. (2008), Theory of planned behaviour, identity and intentions to engage in environmental activism, Journal of Environmental Psychology, 28(4), 318-326.

Fornell C. and Larcker D.F. (1981), Evaluating structural equation models with unobservable variables and measurement error, Journal of marketing research, 18(1), 39-50.

Fransson N. and Garling T. (1999), Environmental concern: conceptual definitions, measurement methods, and research findings, Journal of Environmental Psychology, 19(4), 369-382.

Fujii S. (2006), Environmental concern, attitude toward frugality, and ease of behavior as determinants of proenvironmental behavior intentions, Journal of Environmental Psychology, 26(4), 262-268.

Glasson J., Therivel R. and Chadwick A. (1999), Introduction to Environmental Impact Assessment: Principles and Procedures, Process, Practice, and Prospects: UCL Press.

Glucker A.N., Driessen P.P.J., Kolhoff A. and Runhaar H.A.C. (2013), Public participation in environmental impact assessment: why, who and how?, Environmental Impact Assessment Review, 43(0), 104-111.

Government of Indonesia. (1999). Indonesian government regulation number 27/1999: environmental impact analysis. Jakarta.

Government of Indonesia. (2009). Law No. 32/2009: Environmental protection and management. Jakarta.

Government of Indonesia. (2012). Indonesian government regulation number 27/2012: environmental permit. Jakarta.

Hair J., Anderson R., Tatham R., and Black W. (1998), Multivariate data analysis with readings: Prentice Hall (Englewood Cliffs, NJ).

Han H., Hsu L.-T. and Sheu C. (2010), Application of the Theory of Planned Behavior to green hotel choice: Testing the effect of environmental friendly activities, Tourism Management, 31(3), 325-334.

Hooper D., Coughlan J. and Mullen M. (2008), Structural equation modelling: guidelines for determining model fit. Articles, 2.

Janssen R. (2001), On the use of multi-criteria analysis in environmental impact assessment in The Netherlands, Journal of Multi-Criteria Decision Analysis, 10(2), 101-109.

Jim C.Y. (2004), Green-space preservation and allocation for sustainable greening of compact cities, Cities, 21(4), 311-320.

Kaya T. and Kahraman C. (2011), An integrated fuzzy ahp-electre methodology for environmental impact assessment, Expert Systems with Applications, 38(7), 8553-8562

Lavergne K.J., Sharp E.C., Pelletier L.G. and Holtby A. (2010), The role of perceived government style in the facilitation of self-determined and non self-determined motivation for pro-environmental behavior, Journal of Environmental Psychology, 30(2), 169-177.

Lin S.-C., Persada S.F. and Nadlifatin R. (2014), A study of student behavior in accepting the blackboard learning system: A technology acceptance model (tam) approached. in Computer Supported Cooperative Work in Design (CSCWD), Proceedings of the 2014 IEEE 18th International Conference on IEEE, 457-462.

Lucas K., Brooks M., Darnton A. and Jones J.E. (2008), Promoting pro-environmental behaviour: existing evidence and policy implications, Environmental Science and Policy, 11(5), 456-466.

McKee D. and Wang G. (2006), Economic versus social exchange in marketing places: An empirical study among manufacturing firms, Journal of Business Research, 59(4), 397-406.

Ministry of Environment of Indonesia. (2012a). Ministry of Environment of Indonesian government regulation number 05/2012: Type of business plan and or activities required to have an environmental impact assessment. Jakarta.

Ministry of Environment of Indonesia. (2012b). Ministry of Environment of Indonesian government regulation number 16/2012: Guidelines for environmental document arrangement. Jakarta.

Ministry of Environment of Indonesia. (2012c). Ministry of Environment of Indonesian government regulation number 17/2012: Guidelines for community involvement in environmental impact assessment process and environmental permit. Jakarta. 
Ministry of Environment of Indonesia. (2013). Ministry of Environment of Indonesian government regulation number 08/2013: Procedures on assessment and environmental document inspection plus the environmental permit issuance. Jakarta.

Nadlifatin R., Razif M., Lin S.C., Persada S.F. and Belgiawan P.F. (2015), An assessment model of Indonesian citizens' intention to participate on environmental impact assessment (EIA): a behavioral perspective, Procedia Environmental Sciences, 28, 3-10.

Nunnally J.C. (1978), Psychometric theory. New York: McGraw-Hill.

O'Faircheallaigh C. (2010), Public participation and environmental impact assessment: Purposes, implications, and lessons for public policy making, Environmental Impact Assessment Review, 30(1), 19-27.

Park N. and Yang A. (2012), Online environmental community members' intention to participate in environmental activities: An application of the theory of planned behavior in the Chinese context, Computers in Human Behavior, 28(4), 1298-1306.

Persada S.F., Razif M., Lin S.C. and Nadlifatin R. (2014), Toward Paperless Public Announcement on Environmental Impact Assessment (EIA) through SMS Gateway in Indonesia, Procedia Environmental Sciences, 20, 271-279.

Pimentel D., Cooperstein S., Randell H., Filiberto D., Sorrentino S., Kaye B., Nicklin C., Yagi J., Brian J., O’Hern J., Habas A., and Weinstein C. (2007), Ecology of Increasing Diseases: Population Growth and Environmental Degradation, Human Ecology, 35(6), 653-668.

Tan M. and Teo T.S. (2000), Factors influencing the adoption of Internet banking, Journal of the AIS, 1 (1es), 5.

Tang S.-Y., Tang C.-P. and Lo C.W.-H. (2005), Public participation and environmental impact assessment in mainland China and Taiwan: political foundations of environmental management, The Journal of Development Studies, 41(1), 1-32.

Wanderer T. and Herle S. (2015), Creating a spatial multi-criteria decision support system for energy related integrated environmental impact assessment, Environmental Impact Assessment Review, 52(0), 2-8.

Xian G., Crane M. and Su J. (2007), An analysis of urban development and its environmental impact on the Tampa Bay watershed, Journal of Environmental Management, 85(4), 965-976.

Zimmer-Gembeck M.J., Chipuer H.M., Hanisch M., Creed P.A. and McGregor L. (2006), Relationships at school and stageenvironment fit as resources for adolescent engagement and achievement, Journal of Adolescence, 29(6), 911-933. 